\title{
Organic Agricultural Analysis: Efficiency of Common Practices
}

Bradley Biega

University of South Florida

\author{
Advisors: \\ Arcadii Grinshpan, Mathematics and Statistics \\ Travis Hansen, Sweetwater Organic Farm Manager, Tampa \\ Problem Suggested By: Travis Hansen and Bradley Biega
}

Follow this and additional works at: https://digitalcommons.usf.edu/ujmm

Part of the Mathematics Commons

UJMM is an open access journal, free to authors and readers, and relies on your support:

Donate Now

\section{Recommended Citation}

Biega, Bradley (2018) "Organic Agricultural Analysis: Efficiency of Common Practices," Undergraduate Journal of Mathematical Modeling: One + Two: Vol. 8: Iss. 2, Article 1.

DOI: http://doi.org/10.5038/2326-3652.8.2.4888

Available at: https://digitalcommons.usf.edu/ujmm/vol8/iss2/1 


\title{
Organic Agricultural Analysis: Efficiency of Common Practices
}

\begin{abstract}
To analyze the efficiency of common watering practices in an organic agriculture setting we use Sweetwater Organic Farm's conventional methods for irrigation and land allotment as well as some algebra and calculus technique. Sweetwater's operation is limited to their largest growing field. A mathematical model is built to determine the current efficiency of the rotary head sprinkler system. Then the efficiency of this system is compared to a new drip line system. Several variables like soil porosity, absorption rates, and areas where no plants are located, are taken into consideration. Our results show that the current irrigation in place wastes upwards of 200,000 gallons of water a year and that the proposed drip line irrigation system is more efficient and worth investigating.
\end{abstract}

\section{Keywords}

Organic Agriculture, watering efficiency optimization, interpolation

\section{Creative Commons License}

(c) (i) $\Theta$

This work is licensed under a Creative Commons Attribution-Noncommercial-Share Alike 4.0 License. 


\section{PROBLEM STATEMENT}

Current rotary watering systems are commonplace, but whether they are the best option in terms of cost and watering efficiency. In the paper, the watering efficiency at an organic farm is explored and the efficiency in terms of water that is wasted due to water landing on the walking paths and watering outside the plant bed boundaries is calculated. Then we look at the cost of watering by the rotary sprinklers and explore if it makes sense to migrate to a drip line irrigation system.

\section{MOTIVATION}

With the recent surge in organic food consumption, many organic farms have popped up to take advantage of the booming market. What was only a niche market, has now grown into prominence with almost every major grocery store carrying organic products in one form or another. There is a significant price difference between organic foods and standard foods, namely, due to the increased expenditure in running an organic farm versus a conventional farm. Increasing efficiency in an organic farm equates to greater savings, lower food prices, and reducing environmental impact. Farms can save more money by using fewer resources like water or fertilizer. Farms can pass on these savings to the consumer by lowering food prices, allowing organic food to appeal to a wider audience. Using fewer resources is overall less taxing to the environment, which leads to a greener practice.

\section{MATHEMATICAL DESCRIPTION AND SOLUTION APPROACH}

The field that we look at is $57.91 \mathrm{~m}$ long by $30.48 \mathrm{~m}$ wide. Sprinklers are placed $3.05 \mathrm{~m}$ apart going horizontally across the field. The vertical rows of sprinklers are then placed $6.1 \mathrm{~m}$ apart. 
This allows 100 percent coverage of the field, with 2 sprinklers intersecting any given area (Figures 1 and 2).

Figure 1: Overview of farm

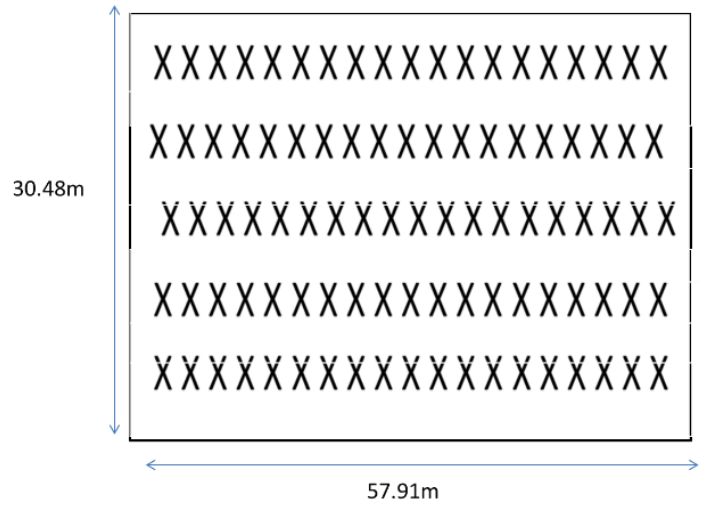

Figure 2: Cross section of row

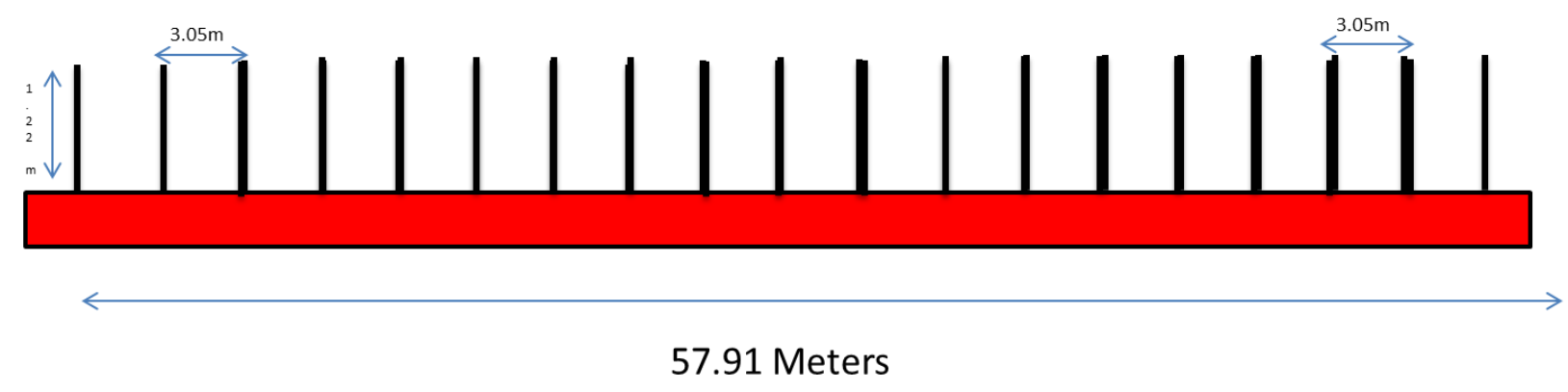

\section{Irrigation Efficiency}

Sweetwater currently makes use of a pivot rotational irrigation system to keep their crops watered. The sprinkler head on top of the irrigation system sits 1.22 meters off the ground and rotates 360 degrees clockwise to distribute water. One issue we need to address is the assumption of uniform distribution of water to all the areas the sprinklers hit (Figure 3). ${ }^{8}$ 
Figure 3: Overlap of Sprinklers

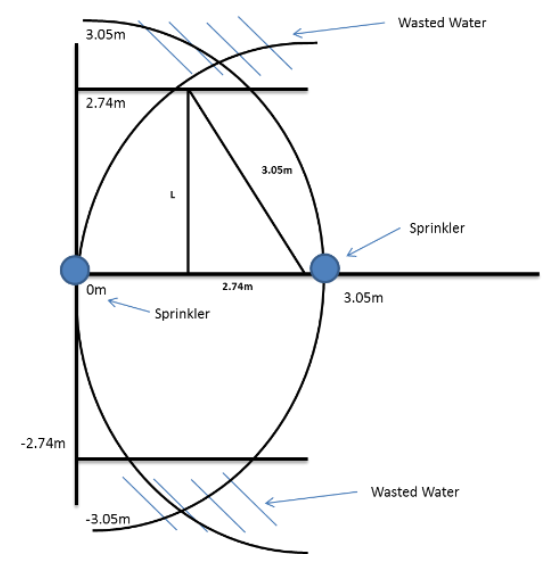

Figure 3 shows how the sprinklers actually overlap in the field. The growing field can be thought of as containing 95 of these blocks. In actuality, the distribution is not uniform over this $6.1 \mathrm{~m}$ by $3.05 \mathrm{~m}$ block. The purpose of a sprinkler is to spread a flow of water over an area. During this process, the water flow is broken up into thousands of droplets, varying in size, usually ranging from $0.5 \mathrm{~mm}$ to $4 \mathrm{~mm}$ in diameter. ${ }^{4}$ The smaller drops do not travel as far as the larger drops, and a well-made sprinkler is going to ensure that larger drops are relatively scarce. This way, more water falls near the sprinkler, as depicted below in Figure 4.

Figure 4: Droplet size relative to distance from sprinkler

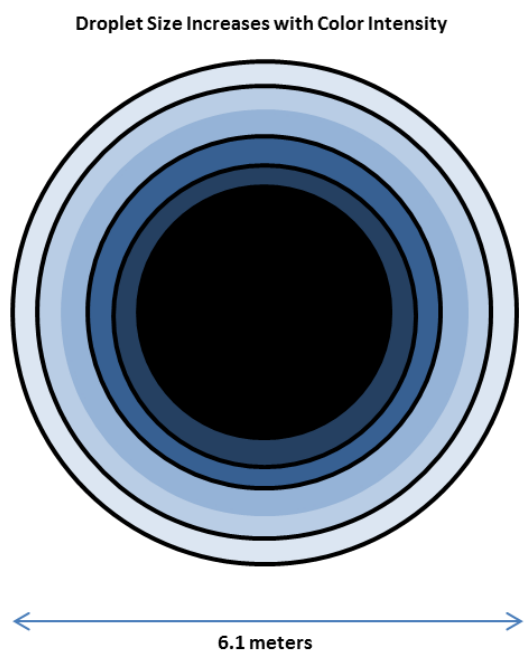


There is some debate on the exact model to be used for this type of watering, but after some research, we assume a paraboloid distribution. ${ }^{4,12}$

\section{Current System}

When calculating the efficiency of the current irrigation system, several assumptions are made to simplify calculations:

1. Natural precipitation has a negligible impact.

2. Farmland is relatively flat.

3. Air resistance is negligible considering the projectile motion of individual water droplets.

4. Currently, crops are watered three days a week for 15-minute sessions. The soil's composition is sandy loam and can absorb around $2.5 \mathrm{~cm}$ of water an hour. There is one retention pond situated to the front of the farm. The farm is built on a slight incline, which allows any excess run off to drain into the retention pond.

5. Flow rate from the pump throughout the system is uniform.

6. Water pressure is uniform throughout entire system, nozzle diameter size and pressure were given to us at 5/32in and 50psi respectively. ${ }^{7}$

7. Irrigation system is a closed loop system.

8. Water leaves sprinkler head at a thirty-degree angle. The sprinkler heads rotate around a horizontal plane, 360 degrees.

9. We assume there are no other phenomena that would skew our data.

10. We assume that water that lands in the walk rows and sprinkler beds are out of reach for plant consumption.

\section{Analysis of the Current Water Distribution System}

To accomplish the analysis of this configuration requires a great deal of computation. The

first thing we need to do is to determine the water application rates based on the selected paraboloid distribution (Figure 5). 
Figure 5: Paraboloid distribution of water droplets ${ }^{11}$

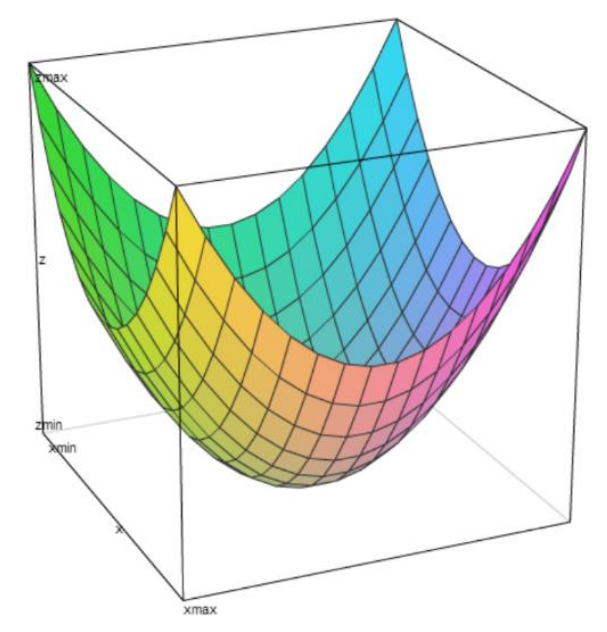

It is necessary since the depths of the water will vary based on the distance it falls from the sprinkler head. Also, in this configuration, there is water that is sprayed outside the boundaries of the plot. It is true in both the top and bottom of the plot. It may not appear to be that much, but in today's environment with dwindling resources, we want to quantify how much water is being wasted by this overspray.

Since there are only two sprinklers operating in any one area at a time, we are able to break the problem down and look at a single $6.1 \mathrm{~m}$ by $3.05 \mathrm{~m}$ plot of land at a time, see Figure 1 . The actual field is made up of 95 of these blocks. We will look at an area on the outer border since this is where the over spray occurs, plus mathematically, it is a more challenging problem than the blocks in the center of the field. As a reminder, the nozzle size of the sprinkler is $5 / 32$ inches with the pressure in the pipes set at 50 psi. The flow of water from these sprinklers is 5 gallons of water a minute, as shown by Table 1 in the appendix. ${ }^{7}$ 
Since we assume a paraboloid distribution of water, we have a parabolic cross section. Now the task is to come up with a formula that describes the water distribution surface. Using the parabolic cross-section, we can determine a maximum depth of the water distribution (z-axis) and then finally determine the equation for our surface.

The first task is to find the water application rate for the sprinkler head. This is the amount of water spread over a given area in an hour (1-2):

$A R=\frac{(96.25)(A \times B)}{C}$,

where 96.25 is a constant that converts $\mathrm{gal} / \mathrm{min}$ into in/hr,

$A=$ number of sprinklers, $B=$ Flow rate $(\mathrm{gal} / \mathrm{min}), C=\frac{\pi r^{2}}{2} f t^{2}$ of watering area.

With $r$ being the radius of the water stream we divide by 2 since each sprinkler contributes a half circle. Radius of sprinkler is $10 \mathrm{ft}=3.05 \mathrm{~m}$. Therefore

$A R=\frac{(96.25)(5)}{(3.14)\left(10^{2}\right)(.5)}=3.065 \mathrm{in} / \mathrm{hr} \quad$ and converting to metric $\mathrm{AR}=7.79 \mathrm{~cm} / \mathrm{hr}$.

This is for one sprinkler. The math on the following pages will take into account that there are two sprinklers per watering block. Using calculus, we want to measure the maximum amount of water in the parabolic cross section. Since the application rate is $7.79 \mathrm{~cm} / \mathrm{hr}$, water $\mathrm{max}_{\text {will }}$ be a higher number.

The equation for our parabola is $x=\sqrt{y}$. We want to find the line where the area above the line is equal to the area below the line giving us the idea on how the water is distributed (3-6):

$\int_{0}^{b} \sqrt{y} d y=\int_{b}^{1} \sqrt{y} d y$, 
$\int_{0}^{b} \sqrt{y} d y=\frac{2 b^{\frac{3}{2}}}{3}$

$\int_{b}^{1} \sqrt{y} d y=\frac{2}{3}-\frac{2 b^{\frac{3}{2}}}{3}$

Therefore,

$\frac{2 b^{\frac{3}{2}}}{3}=\frac{2}{3}-\frac{2 b^{\frac{3}{2}}}{3} \quad$ and $\quad b=.5^{2 / 3} \approx 0.63$

In this case, the areas are equal when $y=0.63$; number 0.63 means that the average value of water distribution is $63 \%$ of the maximum value. Now we can calculate the maximum water point:

Water $_{\max }=\frac{7.79}{0.63}=12.37 \mathrm{~cm}=0.1237 \mathrm{~m}$.

The above calculations are done so that we would have a third point on the parabolic cross section so that we can use Lagrange polynomials to form an equation for the cross section. To keep the math simple, we put the measurements in metric form.

Figure 6: Radius of irrigation system

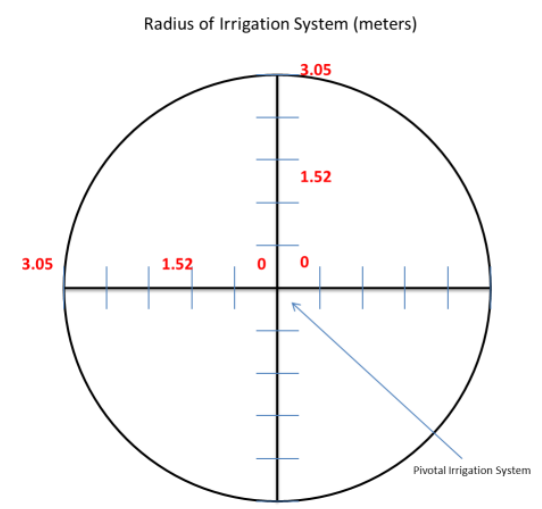

The interpolation points are:

$\left(x_{0}, f\left(x_{0}\right)\right)=(-3.05,0), \quad\left(x_{1}, f\left(x_{1}\right)\right)=(0,-0.1237), \quad\left(x_{2}, f\left(x_{2}\right)\right)=(3.05,0)$. 
So now the corresponding Lagrange polynomial is defined by the formula:

$G(x)=A_{o}(x) f\left(x_{0}\right)+A_{1} f\left(x_{1}\right)+A_{2} f\left(x_{2}\right)$

where

$A_{o}(x)=\frac{\left(x-x_{1}\right)\left(x-x_{2}\right)}{\left(x_{0}-x_{1}\right)\left(x_{0}-x_{2}\right)}, f\left(x_{0}\right)=0$

$A_{l}(x)=\frac{\left(x-x_{0}\right)\left(x-x_{2}\right)}{\left(x_{1}-x_{0}\right)\left(x_{1}-x_{2}\right)}, f\left(x_{1}\right)=-0.1237$

$A_{2}(x)=\frac{\left(x-x_{0}\right)\left(x-x_{1}\right)}{\left(x_{2}-x_{0}\right)\left(x_{2}-x_{1}\right)}, f\left(x_{2}\right)=0$.

Since $A_{0}(x) f\left(x_{0}\right)$ and $A_{2}(x) f\left(x_{2}\right)$ are equal to 0 , we get, see (7-10):

$G(x)=0+\frac{(x-(-3.05))(x-3.05)}{(0-(-3.05))(0-3.05)} \times(-0.1237)=\frac{\left(x^{2}-(3.05)^{2}\right)}{(3.05)^{2}} \times 0.1237=13.3 \times 10^{-3} x^{2}-0.1237$

We can generalize this equation to get the surface equation:

$Z=13.3 \times 10^{-3}\left(\mathrm{x}^{2}+\mathrm{y}^{2}\right)-0.1237$

We established that the area of maximum coverage is the midpoint on the line connecting two sprinklers. This is based on empirical data that we gathered from working on the farm. Also it makes an intuitive sense if you look at the application rates in areas of overlap.

Now we have to add the second sprinkler into the above equation. It is fairly easy to give the new equation as:

$Z=13.3 \times 10^{-3}\left((x-3.05)^{2}+y^{2}\right)-0.1237$.

We assume the origin of the coordinate system is where the first sprinkler is (Figure 6). Therefore, substituting $x=1.525$ (this is the midpoint between two sprinklers) and $y=0$ into the 
above equation gives $Z=-0.093 \mathrm{~m} / \mathrm{hr}$. Since there are 2 sprinklers the total application is doubled. Therefore $\mathrm{Z}=-0.186 \mathrm{~m} / \mathrm{hr}$ or $\mathrm{Z}=-18.6 \mathrm{~cm} / \mathrm{hr}$. As you can see, this is quite a problem since our soil absorption rate is only $2.5 \mathrm{~cm} / \mathrm{hr}$.

Now that we have determined how much water is being used per pair of sprinkler heads, we calculate how much water is being wasted outside the "grow area", in one hour. To do this, we will need to find the point of intersection of the line $y=2.74 \mathrm{~m}$ and circle $y=\sqrt{9.3-x^{2}}$. Using Figure 3 along with the triangle below, we can find the intersection point.

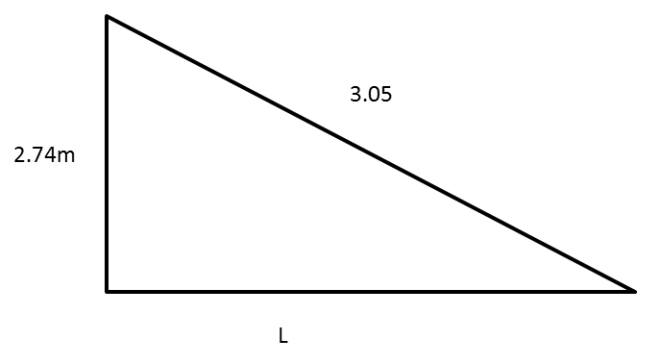

As $(2.74 \mathrm{~m})^{2}+L^{2}=(3.05 \mathrm{~m})^{2}$ and $L=1.34 \mathrm{~m}$, therefore, the intersection point is:

$3.05 \mathrm{~m}-1.34 \mathrm{~m}=1.71 \mathrm{~m}$.

So, to find the water wasted we need to find the volume of the region bounded by

$Z=13.3 \times 10^{-3}\left(x^{2}+y^{2}\right)-0.1237, \quad Z=0 ;$

$Y=\sqrt{(3.05)^{2}-x^{2}}, \quad Y=2.74 \mathrm{~m}$

$X=0$.

This means we should evaluate the corresponding integral, where the upper $x$ limit with respect to the integration is just the point of intersection of the line 
$Y=2.74 \mathrm{~m}$ and circle $\mathrm{y}=\sqrt{9.3-x^{2}}$. A calculator from Wolframalpha.com was used to help solve the double integrals needed for calculations. We obtain $0.0029 \mathrm{~m}^{3}$ of water. This means each sprinkler block on the border wastes $0.0029 \mathrm{~m}^{3}$ of water. Remember, there is a total of 38 blocks that are wasting this much water. It follows that $0.11 \mathrm{~m}^{3}$ of water is sprayed outside the planting area in one hour of watering.

To calculate the total water dispersed for this set of two sprinklers we used the below equation:

$\int_{0}^{3.05} \int_{0}^{\sqrt{9.3-x^{2}}}\left[13.3 \times 10^{-3}\left(x^{2}+y^{2}\right)-0.1237\right] d y d x$

We obtain $-0.4518 \mathrm{~m}^{3}$ of water. Total water disbursed: $0.4518 \times 95=34.34 \mathrm{~m}^{3}$ of water per hour.

Efficiency with overspray is $\frac{0.11}{34.34} \times 100=99.68 \%$.

As you can see, the amount of water lost to being sprayed outside the farming space is almost negligible; however, it does not take the water lost due to runoff into consideration. Each session the sprinklers are only run for 15 minutes so $\frac{18.6}{4}=4.65 \mathrm{~cm}$ of water per session is provided by the sprinklers in the wettest areas of the blocks. As you can see, this is a problem since the absorption rate is $2.5 \mathrm{~cm} / \mathrm{hr}^{15}$

Until the soil becomes saturated with water, it absorbs the water fairly quickly. However, once the soil has become saturated, any excess water is lost almost immediately and becomes runoff. This means a considerable amount of water is lost per session due to runoff. Despite the watering sessions lasting only 15 minutes it has no effect on how long it takes for the soil to become saturated. The soil will slowly percolate $2.5 \mathrm{~cm}$ of water after an hour, however, by that time all the excess water will have drained off, thus being wasted. The amount of water that runs off is outside the scope of this project and we leave it for a future paper. 
Since there are 32 rows of walkways, there is a $9.75 \mathrm{~m}$ by $57.91 \mathrm{~m}$ section of land that has no plants though water is hitting. For a quick calculation, we can say this is approximately 28 blocks of water which means an additional $0.4518(28)=12.65 \mathrm{~m}^{3}$ of water is wasted per hour.

\section{Yearly Water Usage}

Hours of watering in a year are 39 . Total water used per hour is $0.4518 \mathrm{~m}^{3} \times 95$ sprinklers.

Some quick calculations and conversions to gallons give us approximately 442,000 gallons of water put out by the sprinklers in a year. Of 442,000 gallons, almost 131,000 gallons of the total are lost due to spraying outside the farming space or hitting areas without any vegetables.

\section{Water Costs}

In order to keep up with Sweetwater's substantial water use, they obtain their water from the city. Sweetwater is outside of city limits, so their water rates reflect that. The City of Tampa conveniently lists the cost of water on their website. ${ }^{13}$ The price of water is based on a series of tiers. The increased use of water leads to increased costs. The City of Tampa measures water usage in ccf units, where one unit equals 100 cubic feet of water:

442,000 gallons $=591 \mathrm{ccf}, \quad 131,000$ gallons $=175 \mathrm{ccf}$.

$175 \mathrm{ccf}$ is wasted each year and this does not include the runoff, which is significant, but outside the scope of this paper. This will be an ideal project for a later date.

As 175 ccf costs $\$ 1,374$ Sweetwater loses $\$ 1,374$ each year due to inefficient watering practices. The charge per ccf came from Table 2 in the appendix. 


\section{Drip Irrigation}

Now we look at a notional drip irrigation system. The proposed drip system would be on the surface, which requires minimal labor. The drip line of choice, (Agrifim with inline emitters) emits water at $0.52 \mathrm{gal} / \mathrm{hr}$ and has emitters spaced every 24 inches (Figure 7). The drip lines are spaced 12 inches apart, which are optimal for Florida's sandy loam soil. ${ }^{1,9}$ The inspiration behind the proposed system came from a previous experiment done by The Water Management Research Laboratory. $^{2}$

Figure 7: How driplines distribute water ${ }^{2}$

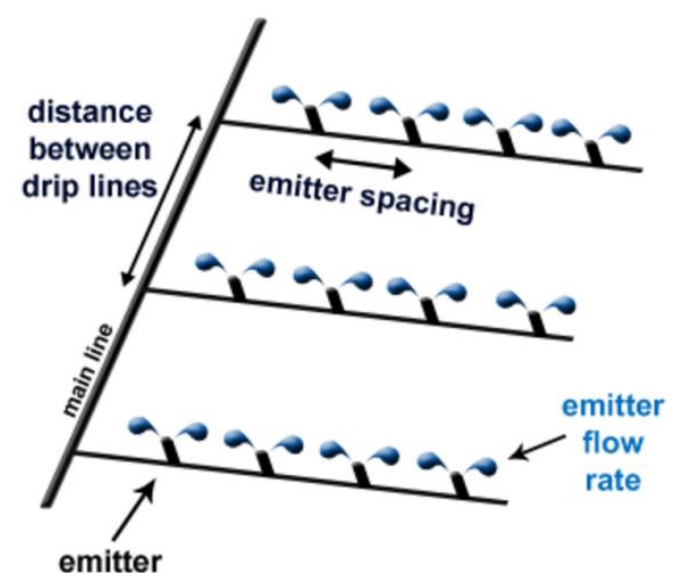

Another excellent feature of drip line irrigation is that it evenly distributes water. With a drip line, water distribution is equal due to a pressure regulator that maintains a constant water pressure level (Figure 8). 
Figure 8: Breakdown of a dripline system ${ }^{3}$

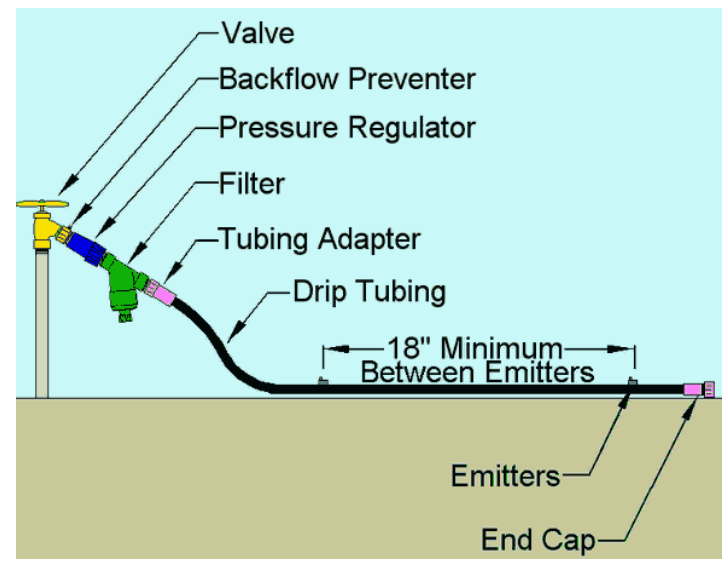

The drip line will be evenly placed through each row of crops. Since there is a pressure regulator, we do not have to worry about water pressure dropping halfway down the line and creating an unequal distribution of water.

\section{DISCUSSION}

The objective of this project was to determine how inefficient Sweetwater's current irrigation system is and if a proposed drip line irrigation system would be more efficient. The objectives were met and the results were as expected. The drip line irrigation system is proposed to be the better system out of two. After panning through a lot of data, the drip line system cames out on top. The results of the problem at hand have much wider implications than at surface value. The results of this project highlight several flaws of Sweetwater's pivotal irrigation system. In such a hot state like Florida, it is important to conserve as much water as possible because during the dry season, water is much harder to come by. Knowing that a drip line system is much more efficient is an important knowledge for a fledgling farmer to have. However, there are drawbacks in this project. Drip line systems work well in Florida because they limit the amount of exposed 
surface area for water, which in turn, lowers evaporation rates. However, in colder environments, threats of water evaporation are much lower and the effort of installing a drip line system wouldn't be worth the return. Also, some plants are foliage feeders, which would actually cause a drip line system to do more harm than good. Pineapples, for example, absorb water through their leaves. A drip line system in this case would be ineffective. Drip line irrigation systems are not always the system of choice for some farmers, however, in the context of this project and based on the needs of Sweetwater, drip lines are the better option.

The Water Management Research Laboratory recommended drip line irrigation as a more efficient way for keeping crops watered. The premise behind drip irrigation is that it works by allowing water to dribble out of an emitter, which saturates the soil over an extended period of time. Increased surface area leads to an increase in evaporation. As in the case with the elevated sprinkler heads, the water has to travel a greater distance through the air before reaching any plants, and given the current temperature, more water could be lost due to evaporation. When using drip irrigation, however, very little water is wasted because less surface area is exposed, reducing evaporation rates. To keep things simple we did not take this into consideration in our calculations, however, if considered, water loss is even greater for the sprinkler system.

Another thing to take into consideration if switching to a drip irrigation system would be the soil composition and length of roots being watered. Instead of selecting an arbitrary length of time to water the soil, a reasonable time can be calculated based on the soil composition and how much water it would take to saturate the entire rooted zone. Figure 9 contains an accurate breakdown of various soil types and their ability to retain water or porosity. 
Figure 9: Soil composition and drainage rates 15

\begin{tabular}{|l|l|l|l|}
\hline Soil texture & $\begin{array}{l}\text { Field capacity }(\% \text { by } \\
\text { vol.) }\end{array}$ & $\begin{array}{l}\text { Wilting point } \\
\text { vol.) }\end{array}$ & $\begin{array}{l}\text { Drainable porosity }(\% \text { by } \\
\text { vol.) }\end{array}$ \\
\hline $\begin{array}{l}\text { clays, clay loams, silty } \\
\text { clays }\end{array}$ & $30-50 \%$ & $15-24 \%$ & $3-11 \%$ \\
\hline well structured loams & $20-30 \%$ & $8-17 \%$ & $10-15 \%$ \\
\hline sandy & $10-30 \%$ & $3-10 \%$ & $18-35 \%$ \\
\hline
\end{tabular}

\section{CONCLUSION AND RECOMMENDATIONS}

Arable land is a finite resource that is steadily being lost every day as people populate more and more of the nation. Instead of focusing on the sheer quantity of acreage for farmland, it is imperative to focus on the quality of each acre. Increasing efficiency is the only way to improve upon current agricultural techniques, which will save both money and valuable resources like water. The overall arching theme of this paper has been centralized around increasing efficiency. In terms of this paper, efficiency is in respect to water usage. Improving efficiency of Sweetwater's irrigation system simply means using less water while maintaining or even improving crop yields.

Increasing the efficiency of the irrigation system at Sweetwater is important to cut down operating costs and increase crop yields. Sweetwater is a non-profit organization, so any savings will allow the farm to expand their operation and further help the surrounding community.

Switching to drip line irrigation would not only save water, but it would also save money as well. Currently, Sweetwater wastes over 131,000 gallons/year of water. Our intuition tells us that this figure, when included with the amount of water lost to runoff, is well over 200,000 gallons/year of water. However, just keeping with the figure of 131,000 gallons, this is a cost of $\$ 1,374$ based on Table 2 in the appendix. The purpose of this paper is not to justify a drip 
irrigation system, but to start the dialogue to determine if the transition is worth it. With the savings shown above and the anticipated costs of a drip irrigation system, we believe that a drip irrigation system will make sense. The costs will be able to be recouped over a short span of years and save millions of gallons of water over the next decade.

Doing a project like this requires more of a hands approach than off. This is not the kind of project where one can look over obscene amounts of data and come to a conclusion. Visiting Sweetwater was a must, however, just once isn't enough. Seeing how the farm reacts under Florida's extreme heat, observing the effects of the placement of an irrigation row on the surrounding beds, and taking note of how excess water drains away from the field after a heavy watering are all things that can't be easily viewed behind a computer screen. Anyone attempting to replicate this project or something similar must be aware that a hand on approach is the better way to go.

There are a lot of directions that this project can be taken in. For one thing, calculating how many more crops can be grown using drip line irrigation would be one example. Also, calculating the actual biomass that could be collected each season using drip line irrigation system would be another idea that could be studied. Science is all about building off the work of one's peers, which will allow for a wide assortment of studies to arise.

\section{NOMENCLATURE}

All units were eventually converted to metric units after solving equations

\begin{tabular}{|l|l|l|}
\hline$L$ & Length & $\mathrm{m}$ \\
\hline$W$ & Width & $\mathrm{m}$ \\
\hline
\end{tabular}




\begin{tabular}{|l|l|l|}
\hline$P R$ & Precipitation rate & $\mathrm{in} / \mathrm{hr}$ \\
\hline$Q_{e}$ & Emitter Flow rate & $\mathrm{gal} / \mathrm{hr}$ \\
\hline Row $_{x}$ & Distance between drip rows & in \\
\hline$r$ & Radius & $\mathrm{m}$ \\
\hline$A$ & Area & $\mathrm{m}^{2}$ \\
\hline Flow Rate & Gallons per minute & $\mathrm{gpm}$ \\
\hline Water $\max$ & Max amount of water & $\mathrm{cm} / \mathrm{hr}$ \\
\hline ccf & Water usage & $\mathrm{ft}^{3}$ \\
\hline
\end{tabular}

\section{REFERENCES}

1. "Agricultural Drainage: Soil Water Concepts." Soil Water Concepts : Agricultural Drainage :

University of Minnesota Extension. Accessed May 03, 2016.

http://www.extension.umn.edu/agriculture/water/agricultural-drainage/soil-water-concepts/.

2. Ayars, J. E., C. J. Phene, R. B. Hutmacher, K. R. Davis, R. A. Schoneman, S. S. Vail, and R. M. Mead. "Subsurface drip irrigation of row crops: a review of 15 years of research at the Water Management Research Laboratory."Agricultural water management 42, no. 1 (1999): 1-27.

3. Camp, C. R. "Subsurface drip irrigation: a review." Transactions of the ASAE41, no. 5 (1998): 1353.

4. Grant, Leah, Jeremy Noe, and Michael Morrison. "Analysis and Optimization of Hand Moved Irrigation Systems." University of Colorado at Denver and Health Sciences Center, February 6, 2006, 1-30. Accessed May 5, 2016. http://math.ucdenver.edu/ golson/Sprinklers.pdf. 
5. Hasegawa, M. "An Adaptive Approach to the Physical Annealing Strategy for Simulated Annealing." Department of Mathematics -- University of Washington, 2013. Accessed May 5, 2016. doi:10.1063/1.4794670.

6. Heermann, D. F., R. A. Kohl, and M. E. Jensen. "Fluid dynamics of sprinkler systems." Design and operation of farm irrigation systems. (1980): 583-618.

7. Hill, Robert W., and Sterling Banks. "SPRINKLERS, CROP WATER USE, AND IRRIGATION TIME." SUMMIT COUNTY, August 2000, 1-8. Accessed March 3, 2016. http://extension.usu.edu/files/publications/publication/ENGR_BIE_WM_09.pdf.

8. Li, Jiusheng. "Modeling crop yield as affected by uniformity of sprinkler irrigation system." Agricultural Water Management 38, no. 2 (1998): 135-146.

9. Master Gardener. St. Paul: Minnesota Extension Service, University of Minnesota, 1995. Accessed May 5, 2016. http://ucanr.edu/sites/scmg/files/30917.pdf.

10. Merriam, John L., and Jack Keller. "Farm irrigation system evaluation: a guide for management." Farm irrigation system evaluation: a guide for management. (1978).

11. Mujumdar, Pradeep P. "Mathematical Tools for Irrigation Water Management An

Overview." International Water Resources Association 27, no. 1 (March 2002): 47-57. Accessed May 5, 2016. http://civil.iisc.ernet.in/ pradeep/My\%20WIN\%20paper.pdf.

12. "Positioning and Moving Sprinkler Systems for Irrigation." Positioning and Moving Sprinkler

Systems for Irrigation, February 6, 2006, 1-42. Accessed April 1, 2016.

https://www.cs.uaf.edu/2006/mcm/gro_irrigation.pdf.

13. "Schedule of Rates." Tampa Government.

http://www.tampagov.net/sites/default/files/water/files/sor.pdf.

14. "The Secrets of Successful Cities." The Metropolitan Century, 2015, 35-77. Accessed May 5, 2016. doi:10.1787/9789264228733-6-en.

15. "Soil Permeability." Fisheries and Aquaculture Department. Accessed May 05, 2016. http://www.mmnt.net/db/0/9/ftp.fao.org/FI/CDrom/FAO_Training/FAO_Training/General/x670 $6 e /$. 


\section{Appendices:}

\begin{tabular}{|c|c|c|c|c|c|c|c|c|c|c|}
\hline \multirow{4}{*}{$\begin{array}{l}\text { Irrigation } \\
\text { Water } \\
\text { Req'd, } \\
\text { inches }\end{array}$} & \multicolumn{10}{|c|}{ Nozzle size, inches } \\
\hline & \multirow{2}{*}{\multicolumn{2}{|c|}{$5 / 32$}} & \multirow{2}{*}{\multicolumn{2}{|c|}{$11 / 64$}} & \multirow{2}{*}{\multicolumn{2}{|c|}{$\begin{array}{c}3 / 16 \\
\text { Pressure psi }\end{array}$}} & \multicolumn{2}{|c|}{$13 / 64$} & \multicolumn{2}{|c|}{$7 / 32$} \\
\hline & & & & & & & & & & \\
\hline & 50 & 60 & 50 & 60 & 50 & 60 & 50 & 60 & 50 & 60 \\
\hline \multicolumn{11}{|c|}{ Irrigation Duration, Hours } \\
\hline 0.5 & 3.6 & 3.3 & 3.0 & 2.7 & 2.5 & 2.3 & 2.2 & 2.0 & 1.9 & 1.7 \\
\hline 1.0 & 7.1 & 6.6 & 5.9 & 5.4 & 5.1 & 4.6 & 4.3 & 4.0 & 3.7 & 3.4 \\
\hline 1.5 & 10.7 & 9.9 & 8.9 & 8.1 & 7.6 & 6.9 & 6.5 & 5.9 & 5.6 & 5.1 \\
\hline 2.0 & 14.2 & 13.2 & 11.9 & 10.8 & 10.2 & 9.2 & 8.7 & 7.9 & 7.4 & 6.8 \\
\hline 2.5 & 17.8 & 16.5 & 14.8 & 13.5 & 12.7 & 11.6 & 10.9 & 9.9 & 9.3 & 8.5 \\
\hline 3.0 & 21.4 & 19.8 & 17.8 & 16.2 & 15.3 & 13.9 & 13.0 & 11.9 & 11.1 & 10.2 \\
\hline 3.5 & 24.9 & 23.1 & 20.8 & 18.9 & 17.8 & 16.2 & 15.2 & 13.8 & 13.0 & 11.9 \\
\hline 4.0 & 28.5 & 26.4 & 23.7 & 21.6 & 20.3 & 18.5 & 17.4 & 15.8 & 14.8 & 13.6 \\
\hline 4.5 & 32.0 & 29.7 & 26.7 & 24.3 & 22.9 & 20.8 & 19.5 & 17.8 & 16.7 & 15.3 \\
\hline 5.0 & 35.6 & 33.0 & 29.7 & 27.0 & 25.4 & 23.1 & 21.7 & 19.8 & 18.5 & 17.0 \\
\hline 5.5 & 39.2 & 36.3 & 32.6 & 29.7 & 28.0 & 25.4 & 23.9 & 21.8 & 20.4 & 18.6 \\
\hline 6.0 & 42.7 & 39.6 & 35.6 & 32.4 & 30.5 & 27.7 & 26.1 & 23.7 & 22.3 & 20.3 \\
\hline 6.5 & 46.3 & 42.9 & 38.6 & 35.1 & 33.1 & 30.1 & 28.2 & 25.7 & 24.1 & 22.0 \\
\hline 7.0 & 49.8 & 46.2 & 41.5 & 37.8 & 35.6 & 32.4 & 30.4 & 27.7 & 26.0 & 23.7 \\
\hline 7.5 & 53.4 & 49.4 & 44.5 & 40.5 & 38.1 & 34.7 & 32.6 & 29.7 & 27.8 & 25.4 \\
\hline 8.0 & 57.0 & 52.7 & 47.5 & 43.2 & 40.7 & 37.0 & 34.7 & 31.6 & 29.7 & 27.1 \\
\hline 8.5 & 60.5 & 56.0 & 50.4 & 45.9 & 43.2 & 39.3 & 36.9 & 33.6 & 31.5 & 28.8 \\
\hline 9.0 & 64.1 & 59.3 & 53.4 & 48.5 & 45.8 & 41.6 & 39.1 & 35.6 & 33.4 & 30.5 \\
\hline 9.5 & 67.6 & 62.6 & 56.4 & 51.2 & 48.3 & 43.9 & 41.2 & 37.6 & 35.2 & 32.2 \\
\hline
\end{tabular}

Table 1

Nozzle size and pressure to water required ${ }^{7}$ 
Water Usage Rate (\$/CCF) Inside Outside

All Other Customer Classes:

City City

Tier 1 Charge per ccf

up to the monthly

threshold ${ }^{*}$ amount .... \$ $2.43 \ldots \ldots \ldots$. 3.03

Tier 2 Charge per ccf for

monthly consumption from

the threshold up to twice the

threshold amount ..... \$ 4.07 ......\$\$ 5.08

Tier 3 Charge per ccf for monthly consumption

from twice the threshold up to

three and one half times the

threshold amount ......\$ $5.44 \ldots \ldots \ldots \$ 6.80$

Tier 4 Charge per ccf for monthly consumption

over three and one half times the

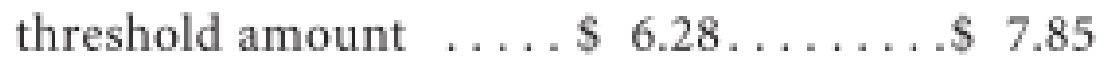

Table 2: City of Tampa water $\operatorname{rates}^{13}$ 